\title{
Effect of Template on the Structure of Carbon Nanotubes Grown by Catalytic Chemical Vapor Deposition Method
}

\author{
Hekmat $\mathrm{F}^{1}$, Sohrabi $\mathrm{B}^{2 *}$ and Rahmanifar $\mathrm{MS}^{1}$
}

${ }^{1}$ Faculty of Basic Science, Shahed University, Tehran, Iran

${ }^{2}$ Department of Chemistry, Surface Chemistry Research Laboratory, Iran University of Science and Technology, Iran

\begin{abstract}
Carbon nanotubes (CNTs) have been synthesized on an anodized aluminum oxide (AAO) template with acetylene by using catalytic chemical vapor deposition (CVD). It was found that the structure of CNTs can be mostly depends on the quality of the catalyst deposition in the pores of AAO template. Straight CNTs were observed when Ni catalyst deposited only in the bottom of holes as nanoparticles, but when Ni catalyst fulfilled the holes of AAO template as nanowires (NWs), coiled CNTs observed. The characterization of as-prepared materials was examined by SEM and Raman spectroscopy. In addition, it is realized that the nanostructure of the AAO template strongly affected the properties of as-grown CNTs. In the other word, based on the obtained results the diameter and pitch of coiled CNTs tightly depend on the size of metallic catalyst and in the results it depend on the pore diameter of AAO template.
\end{abstract}

Keywords: Nanostructures; Chemical vapor deposition; Electron microscopy; Raman spectroscopy

\section{Introduction}

Due to their unique mechanical, electrical, and thermal properties, carbon nanotubes (CNTs) have attracted particular attention among the known allotropes of carbon [1-4]. Although straight CNTs, including single walled CNTs (SWCNTs) and multi walled CNTs (MWCNTs) were commonly observed, different shapes of CNTs such as coiled, branched, and toroidal were reported [5] shortly after their discovering by Iijima [6]. It has been demonstrated that the nanostructure of CNTs can strongly affected the characteristic properties of different shapes of CNTs, so it can limit their applications. For example, unlike straight CNTs, coiled ones can show semi metallic properties beside the typical electrical characteristics of straight CNTs, such as exhibition metallic and semi conductive properties $[7,8]$. Almost simultaneously with claim that there is possibility about the existence of coiled CNTs with minimized energy confirmed by theoretical calculations [9-11] coiled carbon fibers were experimentally synthesized, principally from decomposition of hydrocarbons in the presence of metallic catalyst [12-18]. It is known that coiled CNTs are MWCNTs with incomplete crystalline structures created when paired pentagon-heptagon atomic rings arrange themselves periodically within the hexagonal carbon network. We have previously reported production of a novel porous coiled CNT/ Ni-NW nanostructure by ambient thermal-CVD [19] successfully. Our investigations show that this material being a sufficient structure for improvement of electrode materials for advanced energy storage systems. On the other hand, there is a great interest for growing well aligned CNTs and specially vertically aligned CNTs (VACNTs) for developing field emission devices and a large variety of microelectronic devices, including nanotube sensors, optoelectronic systems, batteries, and supercapacitors [20-23]. One of the common methods for growing VA-CNTs is based on using a porous filter such as AAO template. By using this kind of nano template for growing CNTs, control the shape of CNTs being easy. So, the characteristic properties of CNTs especially their aspect ratios are tightly control with the nanostructure of template, including diameter and length of nano channels. Ever since the discovery of carbon nanotubes, a variety of methods have been reported for producing different shapes of CNTs, among which may be mentioned the following main methods: arc discharge, laser ablation, and CVD [21]. In the last few years, CVD method attracted much attention as the most utilized method, because it is a cost effective method for large-scale production of CNTs on a wide range of substrates. Recently, CVD method is given special emphasis as the most used method for synthesis different shapes of CNTs, specially coiled and aligned straight ones [22-24]. In this study, acetylene decomposition was performed over $\mathrm{Ni}$ catalysts supported on AAO template to investigate the role of catalyst on the structure of as-grown CNTs. To evaluate the effect of nanostructure of AAO template on the appearance of as grown CNTs, different condition of anodizing template, were investigated.

\section{Experimental}

\section{Chemicals}

High-purity aluminum foil (99.9995\%, Merck, Germany), Perchloric acid (60\%, Merck, Germany), ethanol (96\%, Jonoob, Iran), oxalic acid 2-hydrate (99\%, Panreac Quimica SA, E.U.), Choromic anhydride (KANTO Chemical Co. INC, Japan), phosphoric acid (85\%, Merck, Germany), copper sulfate (Merck, Germany), chloridric acid (36\%, Merck, Germany), hexahydrate nickel sulfate (Merck, Germany), heptahydrate nickel chloride (Merck, Germany), boric acid (Merck, Germany) were used as received. Finally, double ionized water was obtained from an OES water purification system (Oklahoma, USA).

\section{Equipments}

DC power supplier (MP6003, Megatek, Germany) was used in order to apply electric field in preparation of AAO template. Electro analyzer system SAMA 500 (Iran) was used for electrochemical deposition of Ni catalytic particles in the pores of AAO template. The samples investigation were done by using scanning electron microscopy (TESCAN, VEGA, Czech Republic), field-emission scanning electron microscope (TESCAN, Mira II and 3 LMU, Czech Republic) and Raman spectroscopy (BRUKER, SENTERRA, Germany).

*Corresponding author: Sohrabi B, Department of Chemistry, Surface Chemistry Research Laboratory, University of Science and Technology, Iran, Tel: +09124948201 E-mail: sohrabi_b@yahoo.com

Received December 13, 2016; Accepted January 02, 2017; Published January 04, 2017

Citation: Hekmat F, Sohrabi B, Rahmanifar MS (2017) Effect of Template on the Structure of Carbon Nanotubes Grown by Catalytic Chemical Vapor Deposition Method. Mod Chem Appl 5: 207. doi: 10.4172/2329-6798.1000207

Copyright: $\odot 2017$ Hekmat $F$, et al. This is an open-access article distributed under the terms of the Creative Commons Attribution License, which permits unrestricted use, distribution, and reproduction in any medium, provided the original author and source are credited. 


\section{Preparation of template and growing CNTs}

As illustrated in Figure 1, a porous AAO template was obtained by two-step anodization of a $3 \times 3 \times 0.3 \mathrm{~mm}^{3}$ high purity $(99.9995 \%$, Merck, Germany) aluminum foil which degreased with acetone by using ultrasonication and then annealed at $500^{\circ} \mathrm{C}$ for $5 \mathrm{hr}$. Before proceeding Aluminum by anodizing, the sample must pretreated using electropolishing for smoothing and brightening the surface of metal. In first step of anodization, the sample was anodized in an aqueous solution of oxalic acid $(0.3 \mathrm{M})$ under a DC constant voltage $(45 \mathrm{~V})$ at low temperature (below $5^{\circ} \mathrm{C}$ ) for 20,22 , and $25 \mathrm{hr}$. After the first step of anodization, the anodized surface layer was removed by electrochemical etching step which occurred in a mixture of chromic acid (1.8 wt \%) and phosphoric acid $(6 \mathrm{wt} \%)$ at $75^{\circ} \mathrm{C}$ for $3 \mathrm{hr}$. In the second step, anodization was done for $4 \mathrm{hr}$ under the same conditions as mentioned in the first step. In order to facilitate the uniform electrodeposition of $\mathrm{Ni}$ which acts as catalyst in growing CNTs, immediately at the end of the second anodization, the voltage was dropped from 45 to $14 \mathrm{~V}$ at the rate of $0.5 \mathrm{~V} \mathrm{~min}{ }^{-1}$. The remaining $\mathrm{Al}$ substrate was mostly removed in a saturated copper sulphate aqueous solution in chloridric acid at room temperature [24]. Finally, the AAO template was etched in a $1 \mathrm{M}$ aqueous solution of phosphoric acid at a room temperature for $40 \mathrm{~min}$ for the further thin the barrier layer and widen the pore size. Catalytic $\mathrm{Ni}$ particles deposited in the nanochannels of as prepared AAO template from Watt bath which contained from hexahydrate nickel sulphate $\left(330 \mathrm{~g} \mathrm{l}^{-1}\right)$, heptahydrate nickel chloride $\left(45 \mathrm{~g} \mathrm{l}^{-1}\right)$ and boric acid $\left(35 \mathrm{~g} \mathrm{l}^{-1}\right)$ at $23^{\circ} \mathrm{C}$ and $\mathrm{pH}=2$. The electrochemical deposition of $\mathrm{Ni}-$ nanoparticles was performed by using AAO template which sputtered with a layer of $\mathrm{Au}$, as working electrode, platinum as counter electrode, and $\mathrm{Ag} / \mathrm{AgCl}$ as reference electrode, and all of the potentials refer to the reference electrode. Ni nanoparticles were electrochemically deposited in nanochannels of AAO template applying at scan rate of $50 \mathrm{mV} \mathrm{s}^{-1}$ in the watt bat contained $\mathrm{NiSO}_{4} \cdot 6 \mathrm{H}_{2} \mathrm{O}, \mathrm{H}_{3} \mathrm{BO}_{3}$, and $\mathrm{NiCl}_{2} .7 \mathrm{H}_{2} \mathrm{O}$. The deposition time was selected by considering the deposition rate of $\mathrm{Ni}$ nanoparticles in the holes of AAO template which is about $8.4 \mathrm{~nm} . \mathrm{s}^{-1}$ [25]. So, we can easily control the mass loading of Ni particles which deposited in the pores of AAO template, by adjusting the deposition time. The deposition of $\mathrm{Ni}$ nanoparticles were carried out in the potential range between -1.1 to $0 \mathrm{~V}$ applying 5 cycles for deposition $\mathrm{Ni}$ nanoparticles and 60 cycles for growing $\mathrm{Ni}$ nanowires (Ni-NWs) which fulfilled the holes of AAO template. Along with fulfilling pores with $\mathrm{Ni}$-NWs, the color of surface changes to silver, so the Ni deposition must be stopped after the first change of color. Figure 2 shows the cyclic voltammograms recorded for deposition $\mathrm{Ni}$ nano catalysts in the pores of AAO template at $23^{\circ} \mathrm{C}$ and $\mathrm{pH}=2$. CNTs were grown by using a catalytic pyrolysis of acetylene as hydrocarbon source and a mixture of hydrogen and argon as carrier gas. In the first step, catalytic Ni particles were reduced in a carrier gas (contains $10 \% \mathrm{H}_{2}$ and $90 \% \mathrm{Ar}$ ) at $500^{\circ} \mathrm{C}$ for $1 \mathrm{hr}$. In the second step, which started immediately after heating up to $650^{\circ} \mathrm{C}$, CNTs were grown by catalytic decomposition of $10 \% \mathrm{C}_{2} \mathrm{H}_{2}$ and $20 \% \mathrm{H}_{2}$ in an $\mathrm{Ar}$ carrier gas at a total flow rate of $150 \mathrm{sccm}$ during 40 min. After growing CNTs, the furnace stay at $650^{\circ} \mathrm{C}$ for $10 \mathrm{~min}$ without any hydrocarbon source, then the furnace was cooled down slowly in presence of Ar. To have free standing VA-CNTs, surrounding AAO template was removed by using $\mathrm{KOH}$ solution in room temperature Figures $3 \mathrm{a}$ and $3 \mathrm{~b}$ illustrate the preparation steps of growing VACNTs and coiled CNTs by using the CVD method, respectively. Our previous studies show that coiled carbon nanotubes grow directly on an anodized aluminum oxide (AAO) template which one side of it is covered with conducting Au layer and the other side is filled by using catalytic Ni nanowires.

\section{Results and Discussion}

\section{Influence of the nanostructure of catalytic $\mathrm{Ni}$ particles on the structure of CNTs}

The Figure 4 show the SEM images of two AAO based templates after deposition of Ni nano catalysts in their pores as nanoparticles and NWs, respectively. As it can be seen in Figure 4a, the catalyst particles deposited uniformly at the bottom of pores and in Figure $4 \mathrm{~b}$, the catalytic Ni-NWs were deposited in the pores of AAO template and filled the holes. Figures $4 \mathrm{c}$ and $4 \mathrm{~d}$ show SEM images of as-grown straight VA-CNTs on the supported $\mathrm{Ni}$ nanoparticles by acetylene decomposition at $650^{\circ} \mathrm{C}$ before and after removing $\mathrm{AAO}$ nano template by using $\mathrm{KOH}$ aqueous solution in room temperature, respectively. Cross sectional and plane views of $\mathrm{AAO} / \mathrm{Ni}-\mathrm{NW}$ based template after growing coiled CNTs on the Ni-NWs were illustrated in Figures $4 \mathrm{e}$ and $4 \mathrm{f}$, respectively. Raman spectroscopy is a method used to obtain suitable information about the structure of as-prepared two kinds of carbon nanotubes. Figure 5 represents the Raman spectra of grown CNTs on the AAO template using Ni nanoparticles and Ni-NWs as catalysts. The multi-walled structure of grown CNTs is identified by the sharp G bands which appeared at $1500-1600 \mathrm{~cm}^{-1}$ region of the wave number and attributed to the graphite $\mathrm{E}^{2} \mathrm{~g}$ optical mode and also by the one observed at the wave number of $1200-1300 \mathrm{~cm}^{-1}$ is known as $\mathrm{D}$ bands which corresponds to the disordered $\mathrm{sp}^{2}$ carbon of graphite [26]. The ID/IG ratio of the as-grown coiled and straight CNTs is $\sim 1.45$ and $\sim 0.865$, respectively. It reveals that the crystallinity of the CNTs grown using Ni nanoparticles as catalyst is higher than that of coiled CNTs grown using Ni-NWs, and it should be noted that increasing the deposition time of Ni particles to fulfill the pores of AAO template can increase the possibility of creating pentagon-heptagon atomic rings within the hexagonal carbon network, which are known as defects $[27,28]$. Thermogravimetric analysis (TGA) was performed to precisely determine the content of coiled CNTs in the coiled CNT/Ni-NW electrode. The results of this analysis has previously been presented by using our group.

\section{Influence of the pore diameter of AAO template on the nano- structure of coil CNTs}

In the CVD process, the size of nano pores which were fulfilled by Ni-NWs play an important role for growing coiled CNTs. SEM observations indicated that the diameter and pitch of as-grown coiled CNTs (Figure 6) were strongly affected by the size of metallic nano catalysts, which was controlled significantly by the pore size

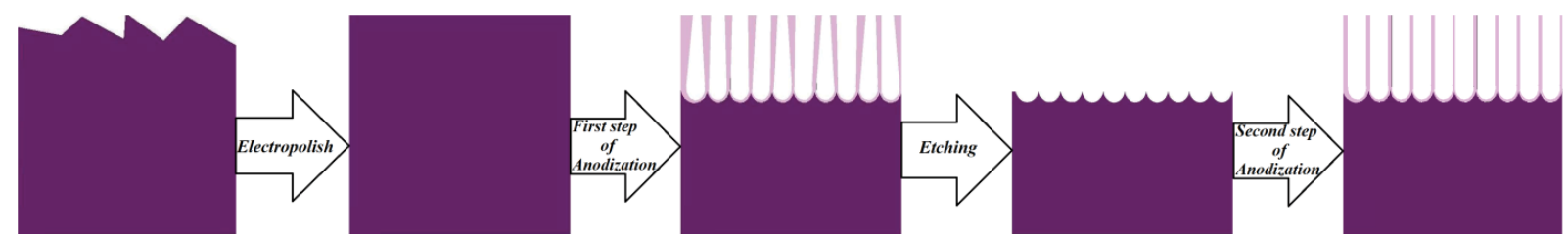

Figure 1: A schematic diagram of experimental setups for the anodization process. 


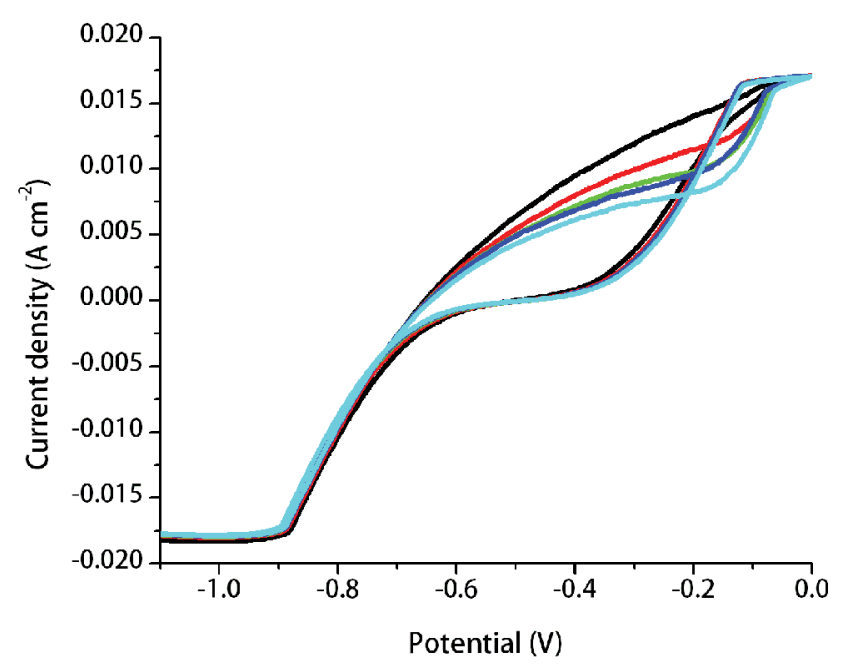

Figure 2: The Ni nano catalysts deposited in the pores of AAO template in Watt bath in scan rate of $50 \mathrm{mVs}^{-1}$.

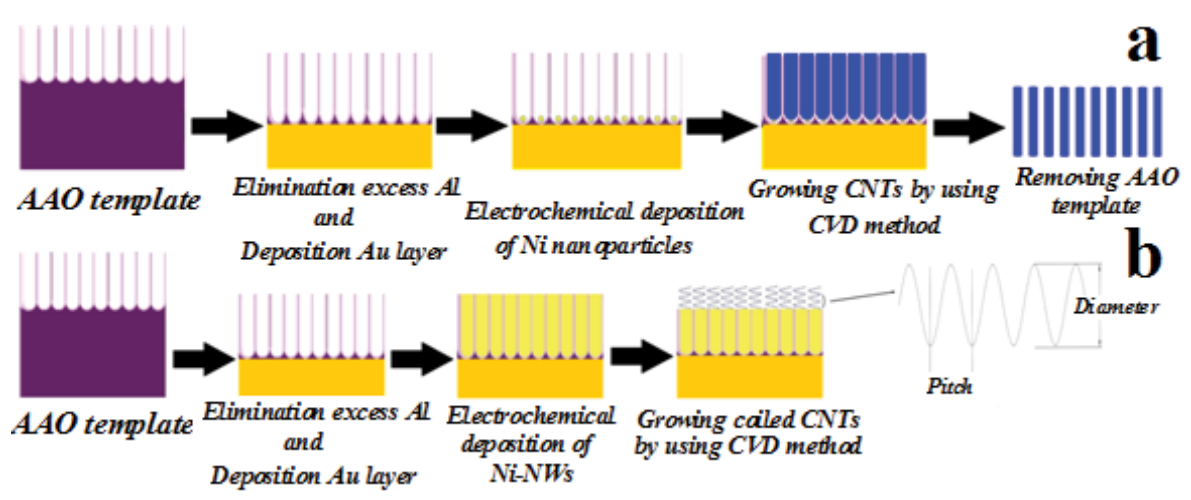

Figure 3: A schematic illustration of growing (a) VA-CNTs and (b) coiled CNTs, by using a catalytic CVD method.
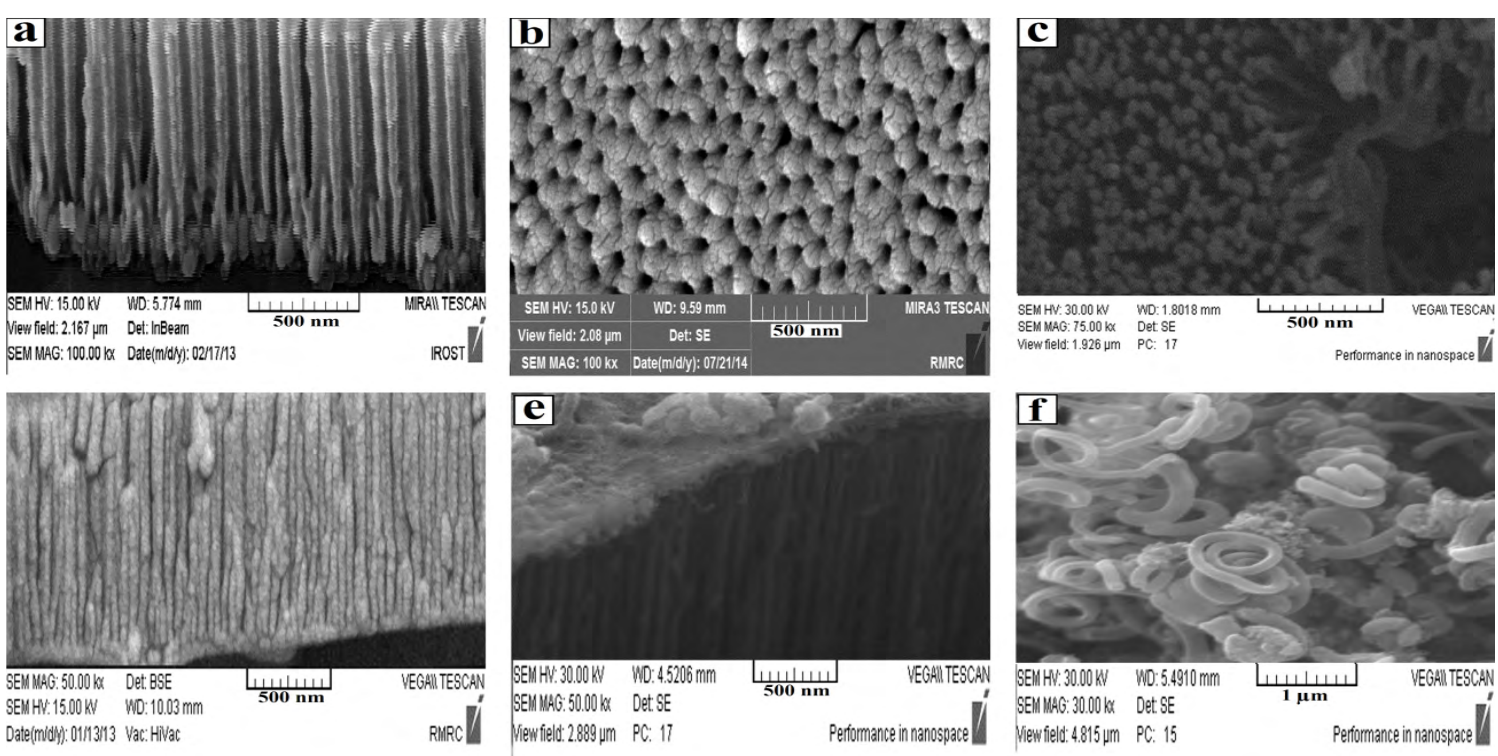

Figure 4: SEM images showing (a) AAO template after deposition Ni nanoparticles in the bottom of pores, (b) and (c) CNTs grown at $650^{\circ} \mathrm{C}$ for 40 min in nanochannels of AAO template before and after removing AAO template, respectively, (d) Ni-NWs deposited in the nanoholes of AAO template, (e) side view and surface morphology of $\mathrm{AAO} / \mathrm{Ni}$ nanowire based template after growing coiled CNTs. 


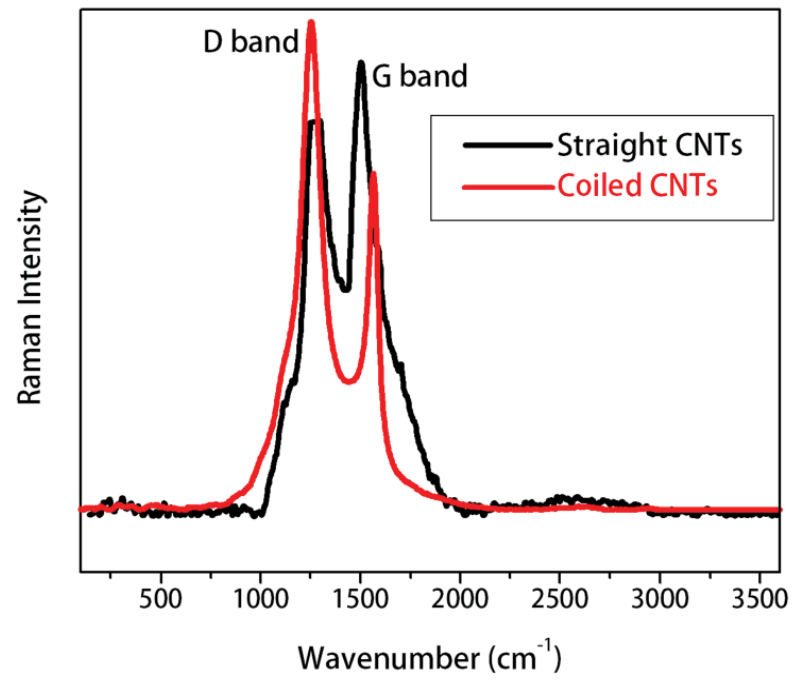

Figure 5: Raman spectrum of the coiled and straight CNTs.
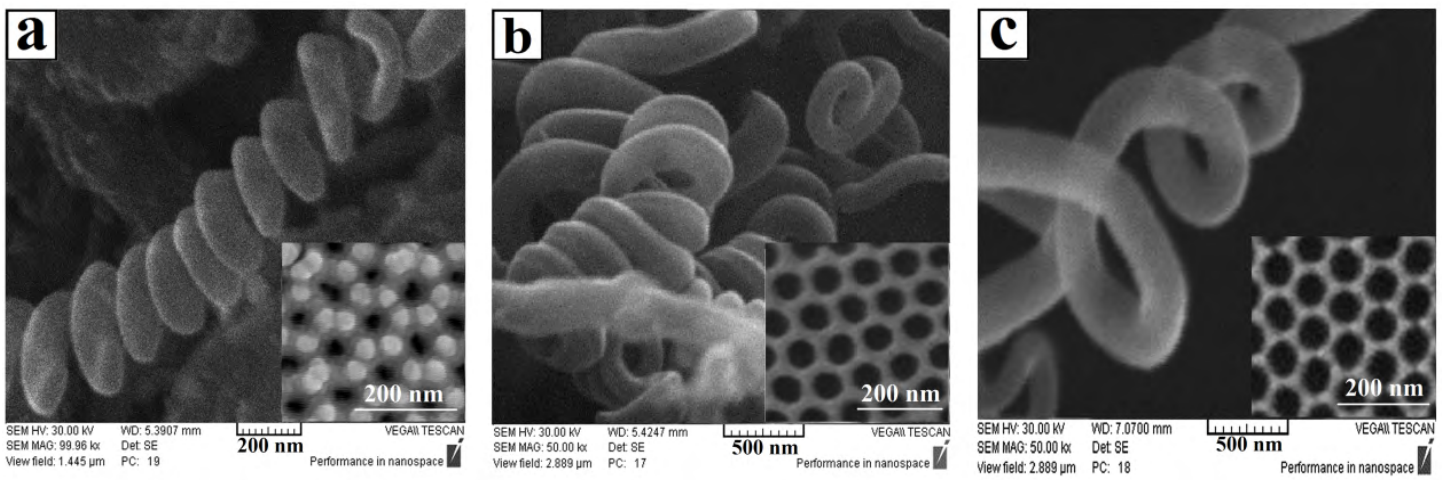

Figure 6: SEM images of coiled CNTs which were grown on the AAO template with pore size of (a) $\sim 50 \mathrm{~nm}$, (b) $\sim 65 \mathrm{~nm}$, (c) $\sim 80 \mathrm{~nm}$.

of AAO template [29]. As it can be seen in Figure 6 diameter, and pitch of coil CNTs were increased by increasing the pore size of AAO template. The insets of Figures $6 \mathrm{a}$ and $6 \mathrm{c}$ show the surface morphology of AAO templates. By increasing the diameter of pores and also the diameter of $\mathrm{Ni}-\mathrm{NWs}$ from $\sim 50$ to $\sim 80 \mathrm{~nm}$, the diameter of coiled CNTs were increased from $\sim 100$ to $\sim 400 \mathrm{~nm}$, respectively. Based on the above results we can claim that the diameter and pitch of coiled CNTs are tightly depend on the pore diameter of AAO template [30].

\section{Conclusion}

In summary, two different types of CNTs were successfully fabricated on an AAO template by using CVD method. This study reveals that the structure of metallic catalyst and the size of nanoparticles of metallic catalyst are important parameters in growing CNTs which can strongly affect the microstructure of MWCNTs and also their alignment on the substrate. On the other hand, the diameter and pitch of coil CNTs can significantly controlled by the diameter of nano pores of AAO template. Therefore, results from this investigation can provide additional insight into control of the shape of CNTs and their application in various industrials.

\section{Acknowledgements}

We are grateful for financial support from Iran National Science Foundation (INSF), Iran (Grant No. 93/36575).

\section{References}

1. Patole SP, Kim HI, Jung JH, Patole AS (2011) The synthesis of verticallyaligned carbon nanotubeson an aluminum foil laminated on stainless steel. Carbon 49: 3522-3528.

2. Bai JB (2003) Growth of nanotube/nano fibre coils by CVD on an alumina substrate. Mater Lett 57: 2629-2633.

3. Beguin F, Presser V, Balducci A, Frackowiak E (2014) Carbons and Electrolytes for Advanced Supercapacitors. Adv Mater 26: 2219-2251.

4. Ismagilov RR, Shvets PV, Zolotukhin AA, Obraztsov AN (2013) Growth of a Carbon Nanotube Forest on Silicon using Remote Plasma CVD. Chem Vap Depo 19: 332-337.

5. Zhang M, Li J (2009) Carbon nanotube in different shapes. Mater Today 12: 12-18

6. lijima S (1991) Helical microtubules of graphitic carbon. Nature 354: 56-58.

7. Lau KT, Lu M, Hui D (2006) Coiled carbon nanotubes Synthesis and their potential applications in advanced composite structures. Compos. Part B Eng 37: $437-448$

8. Csató A, Szabó A, Fonseca A (2012) Synthesis and characterization of coiled carbon nanotubes. Catal Today 181: 33-39.

9. Dunlap BI (1992) Connecting carbon tubules. Phys Rev B 46: 1933-1936.

10. Amelinckx S, Zhang XB, Bernaerts D, Zhang XF (1994) Formation mechanism for catalytically grown helix-shaped graphite nanotubes. Science 265: 635-639.

11. Zhong OY, Su ZB, Wang CL (1997) Coil formation in multishell carbon nanotubes: competition between curvature elasticity and interlayer adhesion Phys Rev Lett 78: 4055-4058. 
Citation: Hekmat F, Sohrabi B, Rahmanifar MS (2017) Effect of Template on the Structure of Carbon Nanotubes Grown by Catalytic Chemical Vapor Deposition Method. Mod Chem Appl 5: 207. doi: 10.4172/2329-6798.1000207

Page 5 of 5

12. Motojima S, Hasegawa I, Kagiya S, Momiyama M (1993) Preparation of coiled carbon fibers by pyrolysis of acetylene using a Ni catalyst and sulfur or phosphorus compound impurity. Appl Phys Lett 62: 2322-2323.

13. Zhang XB, Zhang XF, Bernaerts D, Van G (1994) The Texture of Catalytically Grown Coil-Shaped Carbon Nanotubules. Europhys Lett 27: 141-146.

14. Iwanaga H, Kawaguchi M, Motojima S (1993) A Growth Mechanism of Coiled Whiskers of Silicon Nitride and Carbon. Jpn J Appl Phy 32: 105-115.

15. Itoh S, Ihara S, Kitakami J (1993) Toroidal from of carbon C60. Phys Rev B 47: 1703-1704.

16. Itoh S, Ihara S, Kitakami J (1993) Helically coiled cage forms of graphitic carbon. Phys Rev B 48: 5643-5647.

17. Itoh S, Ihara S (1993) Toroidal forms of graphitic carbon II Elongated tori. Phys Rev B 48: 8323-8327.

18. Liu L, Zhou K, He P, Chen T (2013) Synthesis and microwave absorption properties of carbon coil-carbon fiber hybrid materials. Mater Lett 110: 76-79.

19. Hekmat F, Sohrabi B, Rahmanifar MS, Vaezi MR (2014) Super capacitive properties of coiled carbon nanotubes directly grown on nickel nanowires. J Mater Che A 2: 17446-17453.

20. Chen H, Roy A, Baek JB, Zhu L, Qu J (2010) Controlled growth and modification of vertically-aligned carbon nanotubes for multifunctional applications. Mater Sci Eng R 70: 63-91.

21. Prasek J, Drbohlavova J, Chomoucka J, Hubalek J (2011) Methods for carbon nanotubes synthesis. J Mater Chem. 21: 15872-15884.

22. Quinton BT, Barnes PN, Varanasi CV (2013) A Comparative Study of Three
Different Chemical Vapor Deposition Techniques of Carbon Nanotube Growth on Diamond Films. J Nano mater 356259: 1-9.

23. Khavrus VO, Weiser M, Fritsch M, Leonhardt A (2012) Application of Carbon Nanotubes Directly Grown on Aluminum Foils as Electric Double Layer Capacitor Electrodes. Chem Vapor Depos 18: 53-60.

24. Chemical Vapour Deposition Precursors Processes and Applications (2009) RSC publishing.

25. Yen JH, Leu IC, Wu MT, Lin CC (2004) Density Control for Carbon Nanotube Arrays Synthesized by ICP-CVD Using AAO/Si as a Nano template. Electro chem Solid St 7: 29-31.

26. Chhowalla M, Teo KBK, Ducati C (2001) Growth process conditions of vertically aligned carbon nanotubes using plasma enhanced chemical vapor deposition. J Appl Phys 90: 5308-5317.

27. Shin YS, Hong JY, Ryu DH (2007) The Role of H2 in the Growth of Carbon Nanotubes on an AAO Template. J Korean Phys Soc. 50: 1068-1072.

28. Lu W, Qu L, Henry K (2009) High performance electrochemical capacitors from aligned carbon nanotube electrodes and ionic liquid electrolytes. J Power Sources 189: 1270-1277.

29. Wen S, Mho S, Yeo IH (2006) Improved electrochemical capacitive characteristics of the carbon nanotubes grown on the alumina templates with high pore density. J Power Sources 163: 304-308.

30. Hu W, Yuan L, Chen Z (2002) Fabrication and Characterization of Vertically Aligned Carbon Nanotubes on Silicon Substrates Using Porous Alumina Nano templates. J Nanosci Nanotech 2: 203-207. 